\title{
我
}

\section{Microstructure, Electrical Properties, and Accelerated Aging Behavior of Er-Added ZPCC-YE Varistors}

\author{
Choon-Woo Nahm ${ }^{\dagger}$ and Jong-Hyuk Park \\ Semiconductor Ceramics Laboratory, Department of Electrical Engineering, Dongeui University, Busan 614-714, Korea
}

Received September 14, 2010; Accepted September 20, 2010

\begin{abstract}
The microstructure, electrical properties, and DC-accelerated aging behavior of the Zn-Pr-Co-Cr-Y-Er (ZPCC-YE) varistors were investigated for different amounts of erbium oxide $\left(\operatorname{Er}_{2} \mathrm{O}_{3}\right)$. The microstructure consisted of zinc oxide grain and an intergranular layer $\left(\operatorname{Pr}_{6} \mathrm{O}_{11}, \mathrm{Y}_{2} \mathrm{O}_{3}\right.$, and $\mathrm{Er}_{2} \mathrm{O}_{3}$-rich phase) as a secondary phase. The increase of $\operatorname{Er}_{2} \mathrm{O}_{3}$ amount decreased the average grain size and increased the sintered density. As the $\operatorname{Er}_{2} \mathrm{O}_{3}$ amount increased, the breakdown field increased from $5094 \mathrm{~V} / \mathrm{cm}$ to $6966 \mathrm{~V} / \mathrm{cm}$ and the nonlinear coefficient increased from 27.8 to 45.1 . The ZPCC-YE varistors added with 0.5 to $1.0 \mathrm{~mol} \% \mathrm{Er}_{2} \mathrm{O}_{3}$ are appropriate for high voltage, with high nonlinearity and stability against DC-accelerated aging stress.
\end{abstract}

Keywords: Microstructure, Electrical properties, Accelerated aging behavior, ZPCC-YE varistor ceramics

\section{INTRODUCTION}

Complex electronic systems are vulnerable to damage from transient overvoltage due to weak insulation strength. Progress in the development of faster ICs with higher levels of integration can be accompanied by increased vulnerability [1]. Zinc oxide $(\mathrm{ZnO})$ added with various different metal oxides can be applied to smart semiconducting electronic ceramic devices. Among various $\mathrm{ZnO}$ devices, $\mathrm{ZnO}$-based varistor ceramics possess nonlinear properties, which exhibit abruptly increasing current at a critical value in accordance with increasing voltage. They are manufactured by sintering $\mathrm{ZnO}$ added with various subordinate oxides, such as $\mathrm{Bi}_{2} \mathrm{O}_{3}, \mathrm{Pr}_{6} \mathrm{O}_{11}, \mathrm{CoO}, \mathrm{Cr}_{2} \mathrm{O}_{3}$, etc. They are monolithic devices consisting of many grains of $\mathrm{ZnO}$, mixed with other materials and compressed into a single form. The nonlinearity of voltage-current properties is attributed to the presence of a double Schottky barrier formed at active grain boundaries that contain many trap states. Highly nonlinear properties enable $\mathrm{ZnO}$ ceramics to be used widely in overvoltage protection systems from electronic circuits to electric power systems [2,3].

Recently, Zn-Pr-based varistor ceramics have been studied to further enhance varistor properties and stability against various stresses, such as DC-accelerated aging stress and impulse

\footnotetext{
${ }^{\dagger}$ Author to whom all correspondence should be addressed: E-mail: cwnahm@deu.ac.kr
}

stress [4-16]. Nahm et al. [7-16]. reported that Zn-Pr-Co-Cr-R oxide ( $\mathrm{R}=\mathrm{Er}, \mathrm{Y}, \mathrm{Dy}, \mathrm{La}, \mathrm{Tb})$-based varistor ceramics have highly nonlinear properties and high stability against various stresses. These varistor ceramics are limited to 5 components. To develop varistor ceramics for high performance and wide band applications, it is important to understand the effects of the additives on nonlinear properties. No study of the effects of rare earth oxide (erbium oxide, $\mathrm{Er}_{2} \mathrm{O}_{3}$ ) on the electrical properties and stability of $\mathrm{Zn}$-Pr-based varistor ceramics consisting of 6 components has been reported. In the present study, the effect of $\mathrm{Er}_{2} \mathrm{O}_{3}$ on the microstructure, electric field-current density (EJ) and stability of the Zn-Pr-Co-Cr-Y-Er (ZPCCE-YE) varistor ceramics was examined.

\section{EXPERIMENTAL PROCEDURE}

\subsection{Sample preparation}

Reagent-grade raw materials were used in proportions of (97.5-x) mol\% $\mathrm{ZnO}+0.5 \mathrm{~mol} \% \mathrm{Pr}_{6} \mathrm{O}_{11}+1.0 \mathrm{~mol} \% \mathrm{CoO}+0.5 \mathrm{~mol} \%$ $\mathrm{Cr}_{2} \mathrm{O}_{3}+0.5 \mathrm{~mol} \% \mathrm{Y}_{2} \mathrm{O}_{3}+\mathrm{x}$ mol\% $\mathrm{Er}_{2} \mathrm{O}_{3}(\mathrm{x}=0.25,0.5,1.0)$. Raw materials were mixed by ball milling with zirconia balls and acetone in a polypropylene bottle for 24 hours. The mixture was dried at $120^{\circ} \mathrm{C}$ for 12 hours and calcined in air at $750^{\circ} \mathrm{C}$ for 2 

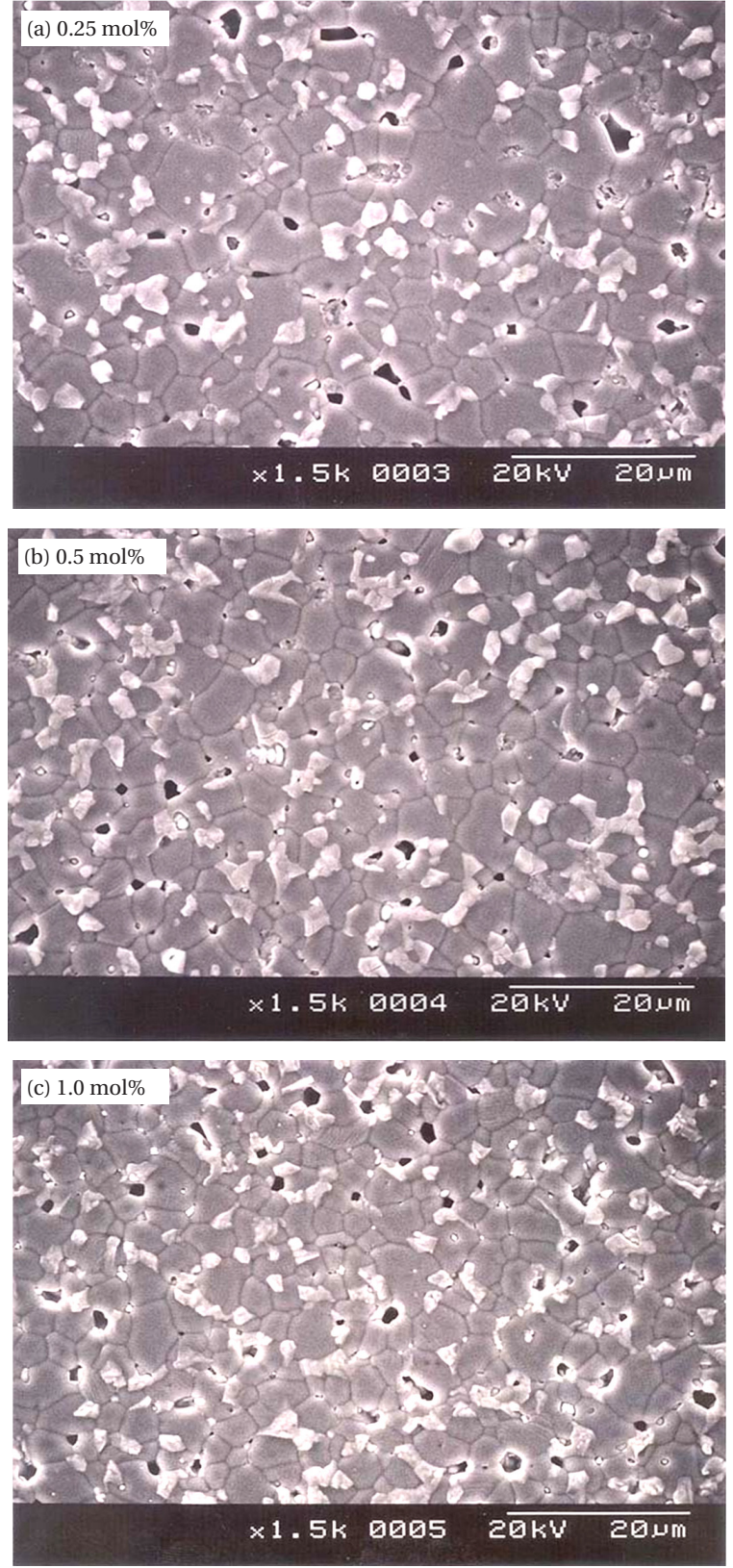

Fig. 1. Micrographs of the samples added with different amounts of $\mathrm{Er}_{2} \mathrm{O}_{3}$.

hours. The calcined mixture was pulverized using an agate mortar and pestle, and (after the addition of $2 \mathrm{wt} \%$ polyvinyl alcohol binder) was granulated by sieving through a 100-mesh screen to produce the starting powder. The powder was uniaxially pressed into discs of $10 \mathrm{~mm}$ in diameter and $2 \mathrm{~mm}$ in thickness at a pressure of $80 \mathrm{MPa}$. The discs were sintered for 1 hour at $1335^{\circ} \mathrm{C}$ and furnace-cooled to room temperature. The heating and cooling rates were $4{ }^{\circ} \mathrm{C} / \mathrm{min}$. The sintered samples were lapped and polished to $1.0 \mathrm{~mm}$ thickness. The final samples were about $8 \mathrm{~mm}$ in diameter and $1.0 \mathrm{~mm}$ in thickness. Silver paste was coated on both faces of the samples, and the silver electrodes were formed by heating it at $600^{\circ} \mathrm{C}$ for $10 \mathrm{~min}$. The electrodes were $5 \mathrm{~mm}$ in diameter.

\subsection{Microstructure examination}

For microstructure characterization, both surfaces of the sam-

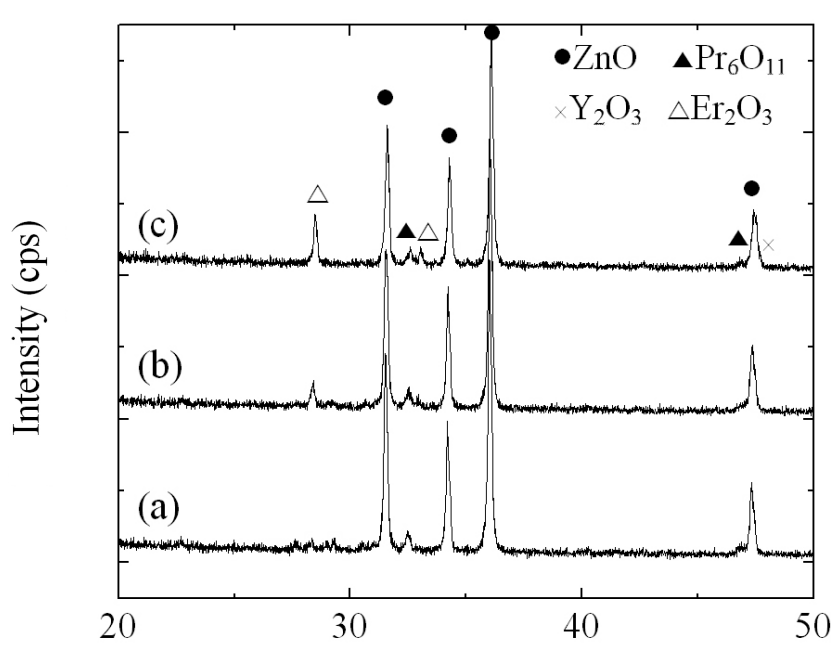

Diffraction angle, $2 \theta$ (deg.)

Fig. 2. X-ray diffraction patterns of the samples added with different amounts of $\mathrm{Er}_{2} \mathrm{O}_{3}$ : (a) $0.25 \mathrm{~mol} \%$, (b) $0.5 \mathrm{~mol} \%$, and (c) $1.0 \mathrm{~mol} \%$.

ples were lapped and ground with SiC paper and polished with $0.3 \mu \mathrm{m}$-Al powder to a mirror-like surface. The polished samples were thermally etched at $1100^{\circ} \mathrm{C}$ for $30 \mathrm{~min}$. The surface microstructure was examined by a scanning electron microscope (SEM, Hitachi S2400, Chiyoda-Ku, Tokyo, Japan). The average grain size (d) was determined by the lineal intercept method, given by $\mathrm{d}=$ $1.56 \mathrm{~L} / \mathrm{MN}$, where $\mathrm{L}$ is the random line length on the micrograph, $\mathrm{M}$ is the magnification of the micrograph, and $\mathrm{N}$ is the number of grain boundaries intercepted by the lines [17]. The compositional analysis of the selected areas was determined by an energy dispersion X-ray spectroscope (EDS) attached to the SEM unit. The crystalline phases were identified by an X-ray diffractometer (XRD, Rigaku D/max 2100, Shibuya-Ku, Tokyo, Japan) using a $\mathrm{CuK}_{a}$ radiation. The sintered density $(\rho)$ was measured using a density determination kit (238490) attached to a balance (Mettler Toledo AG 245, Mettler Toledo International Inc., Greifensee, Switzerland).

\subsection{Electrical measurement}

The electric field-current density (E-J) characteristics were measured using a high voltage source-measure unit (Keithley 237, Keithley Instruments Inc., Cleveland, OH, USA). The breakdown field $\left(\mathrm{E}_{1 \mathrm{~mA} / \mathrm{cm}^{2}}\right)$ was measured at $1.0 \mathrm{~mA} / \mathrm{cm}^{2}$, and the leakage current density $\left(\mathrm{J}_{\mathrm{L}}\right)$ was measured at $0.8 \mathrm{E}_{1} \mathrm{~mA} / \mathrm{cm}^{2}$. In addition, the nonlinear coefficient $(\alpha)$ is defined by the empirical law, $\mathrm{J}=\mathrm{C} \cdot \mathrm{E}^{\alpha}$, where $\mathrm{J}$ is the current density, $\mathrm{E}$ is the applied electric field, and $\mathrm{C}$ is a constant. $\alpha$ was determined in the current density range of $1.0 \mathrm{~mA} / \mathrm{cm}^{2}$ to $10 \mathrm{~mA} / \mathrm{cm}^{2}$, where $\alpha=1 /\left(\log \mathrm{E}_{2}{ }^{-}\right.$ $\log E_{1}$ ), and $E_{1}$ and $E_{2}$ are the electric fields corresponding to 1.0 $\mathrm{mA} / \mathrm{cm}^{2}$ and $10 \mathrm{~mA} / \mathrm{cm}^{2}$, respectively.

\subsection{DC-accelerated aging stress test}

The DC-accelerated aging stress test was performed under four continuous conditions: $0.85 \mathrm{E}_{1 \mathrm{~mA}} / 115^{\circ} \mathrm{C} / 24 \mathrm{~h}$ in the first stress, $0.90 \mathrm{E}_{1 \mathrm{~mA}} / 120^{\circ} \mathrm{C} / 24 \mathrm{~h}$ in the second stress, and $0.95 \mathrm{E}_{1 \mathrm{~mA}} / 125^{\circ} \mathrm{C}$ $124 \mathrm{~h}$ in the third stress. The leakage current was monitored at intervals of 1 min during stressing using a high voltage sourcemeasure unit (Keithley 237). The degradation rate coefficient $\left(\mathrm{K}_{\mathrm{T}}\right)$ was calculated from the expression $\mathrm{I}_{\mathrm{L}}=\mathrm{I}_{\mathrm{LO}}+\mathrm{K}_{\mathrm{T}} \mathrm{t}^{1 / 2}$ [18], where $\mathrm{I}_{\mathrm{L}}$ is the leakage current at stress time $(t)$, and $I_{L o}$ is $I_{L}$ at $t=0$. After the 


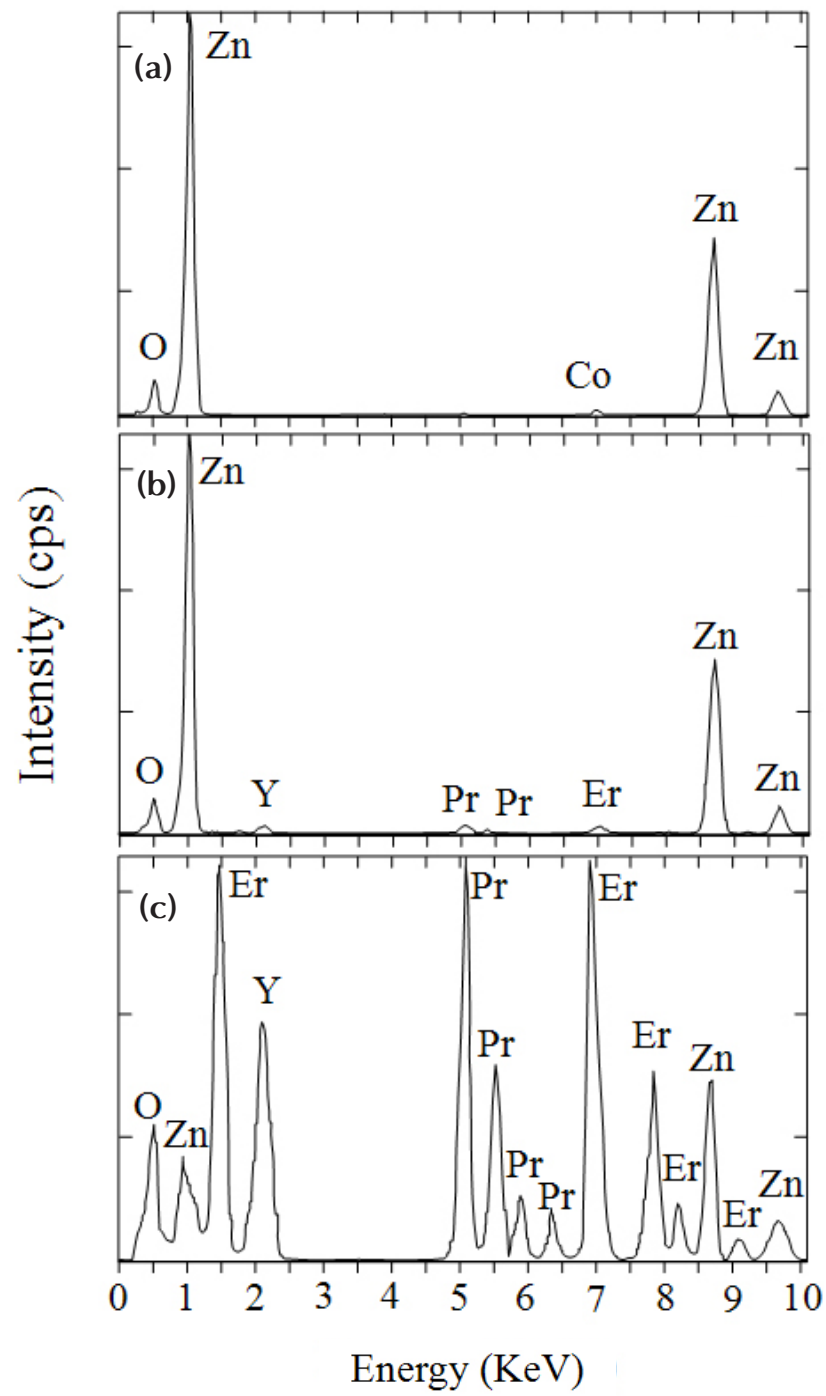

Fig. 3. Energy dispersion X-ray spectroscope spectra of the samples: (a) $\mathrm{ZnO}$ grain, (b) grain boundary, and (c) intergranular layer.

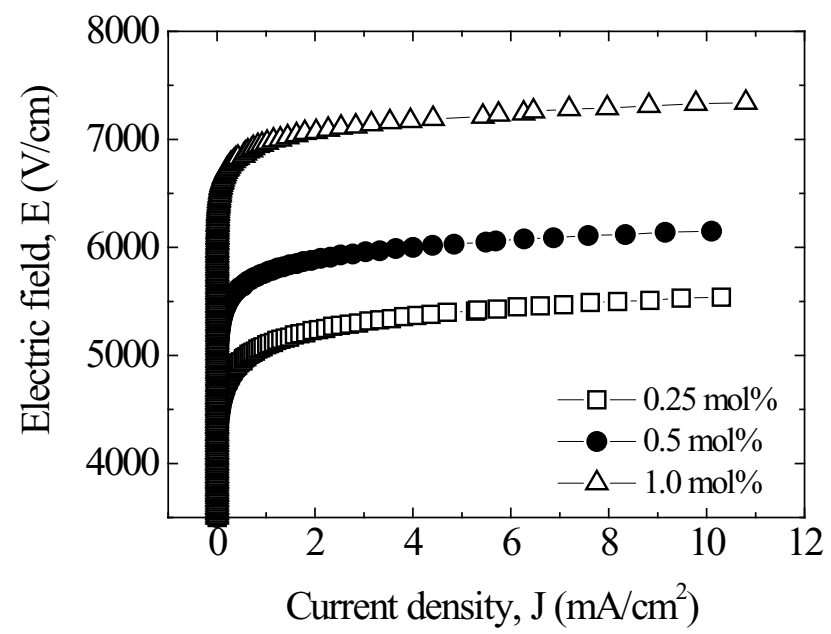

Fig. 4. E-J characteristics of the samples added with different amounts of $\mathrm{Er}_{2} \mathrm{O}_{3}$.

respective stresses, the E-J characteristics were measured at room temperature.

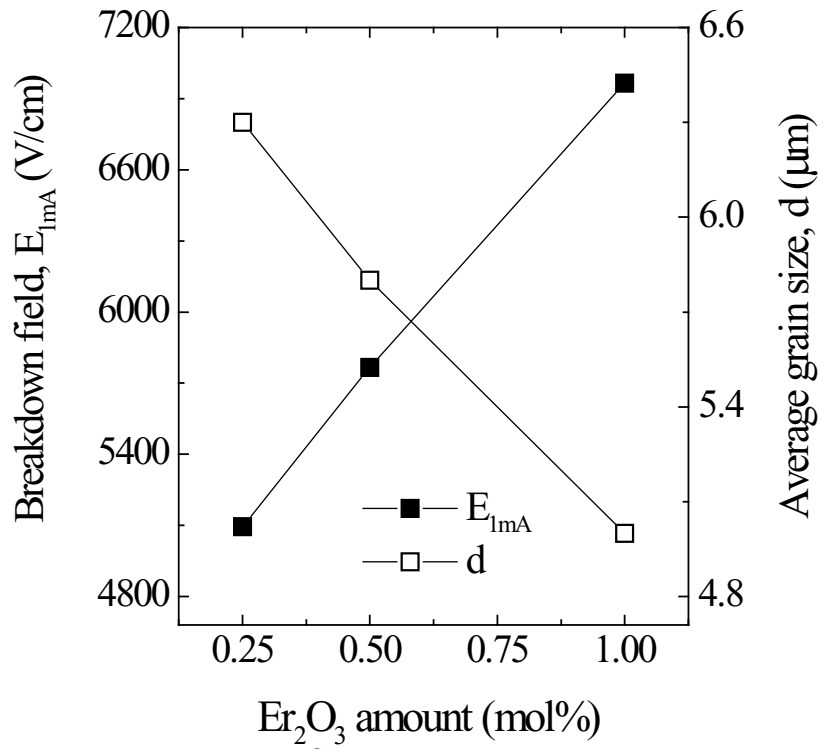

Fig. 5. Breakdown field as a function of $\mathrm{Er}_{2} \mathrm{O}_{3}$ amount.

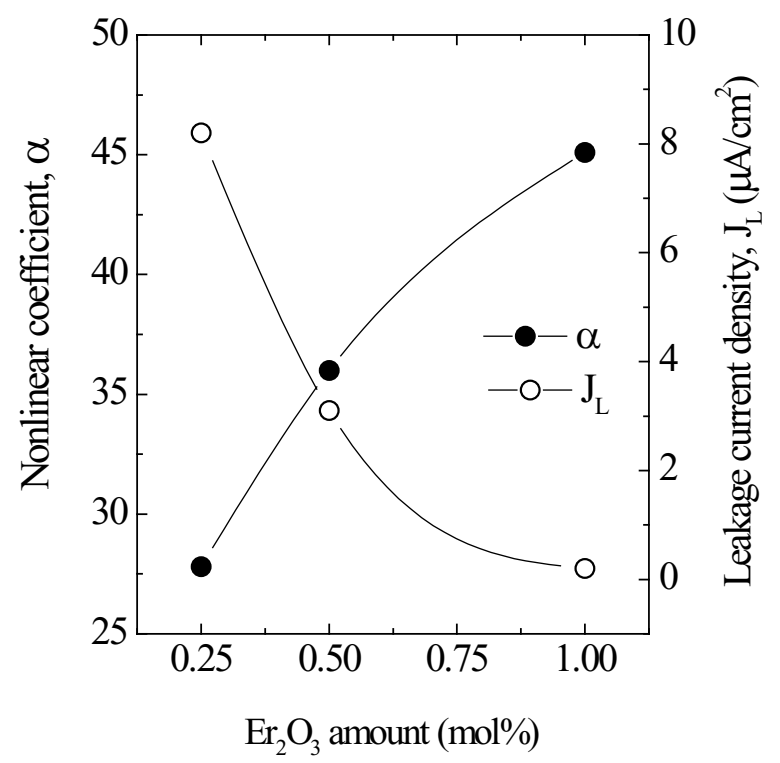

Fig. 6. Nonlinear coefficient and leakage current density as a function of $\mathrm{Er}_{2} \mathrm{O}_{3}$ amount.

\section{RESULTS AND DISCUSSION}

Figure 1 shows SEM micrographs of the samples added with different amounts of $\mathrm{Er}_{2} \mathrm{O}_{3}$. The microstructure consisted of $\mathrm{ZnO}$ grain (black) as a primary phase and an intergranular layer (white) as a secondary phase. The XRD patterns indicated in Fig. 2 confirmed that the secondary phases were $\operatorname{Pr}_{6} \mathrm{O}_{11}, \mathrm{Y}_{2} \mathrm{O}_{3}$, and $\mathrm{Er}_{2} \mathrm{O}_{3}$-rich phases. The EDS spectra in Fig. 3 shows that the $\operatorname{Pr}_{6} \mathrm{O}_{11}, \mathrm{Y}_{2} \mathrm{O}_{3}$, and $\mathrm{Er}_{2} \mathrm{O}_{3}$ are segregated at grain boundaries and nodal points due to an ionic radius difference for $\mathrm{Zn}$, and coexist in the grain boundaries and the nodal points as if they were a single phase. The sintered density $(\rho)$ increased from $5.33 \mathrm{~g} / \mathrm{cm}^{3}$ to $5.45 \mathrm{~g} / \mathrm{cm}^{3}\left(5.78 \mathrm{~g} / \mathrm{cm}^{3}\right.$ in pure $\left.\mathrm{ZnO}\right)$ with the increase of $\mathrm{Er}_{2} \mathrm{O}_{3}$ amount. The average grain size (d) decreased from $6.3 \mu \mathrm{m}$ to 5.0 $\mu \mathrm{m}$. Therefore, the densification of the samples is enhanced by the addition of $\mathrm{Er}_{2} \mathrm{O}_{3}$. The detailed microstructural parameters are summarized in Table 1. 

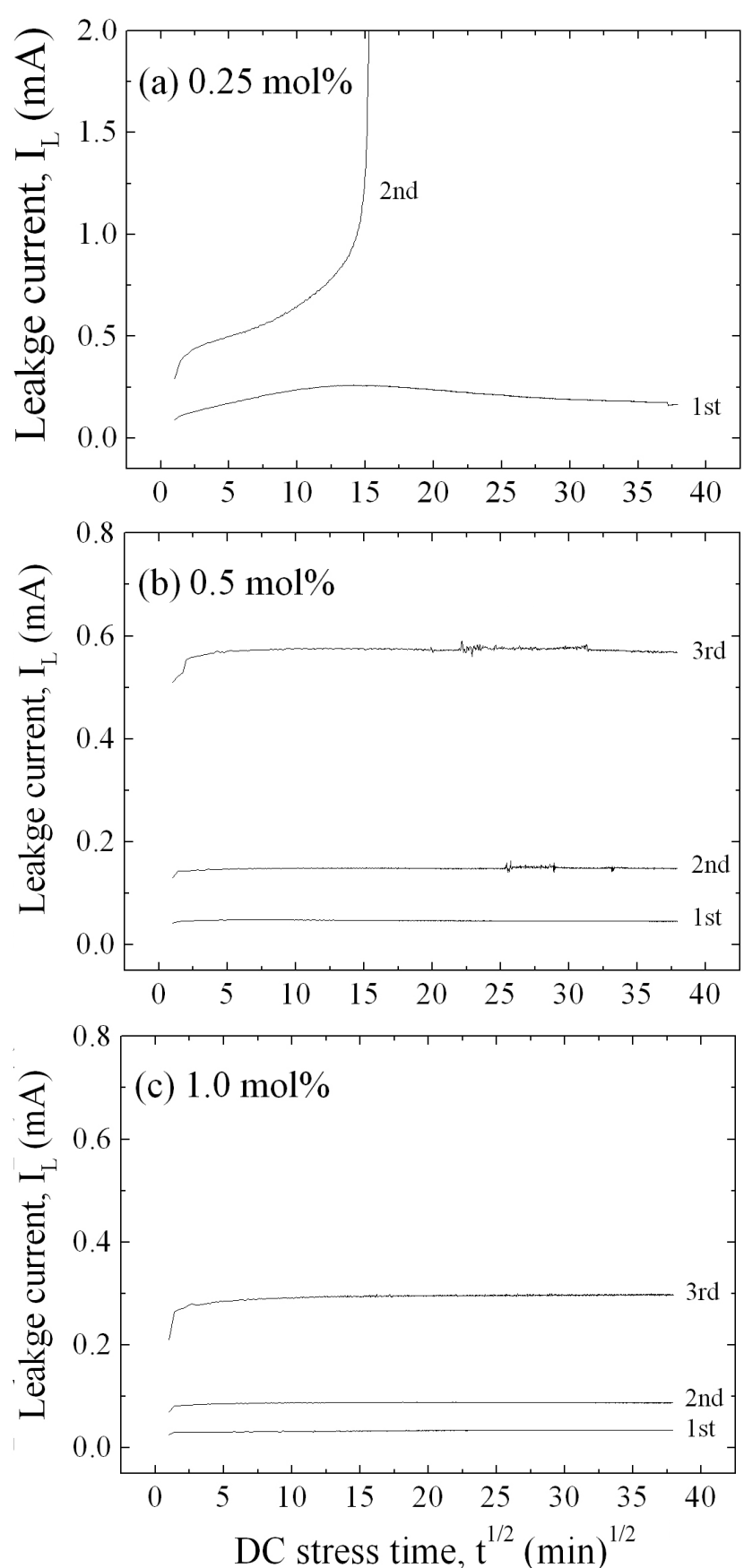

Fig. 7. Leakage current behavior during application of the stress for the samples added with different amounts of $\mathrm{Er}_{2} \mathrm{O}_{3}$.

Table 1. Microstructure and E-J characteristic parameters for the samples added with different amounts of $\mathrm{Er}_{2} \mathrm{O}_{3}$.

\begin{tabular}{lllllll}
\hline $\begin{array}{l}\mathrm{Er}_{2} \mathrm{O}_{3} \\
\text { amount } \\
(\mathrm{mol} \%)\end{array}$ & $\begin{array}{l}\mathrm{d} \\
(\mu \mathrm{m})\end{array}$ & $\begin{array}{l}\rho \\
\left(\mathrm{g} / \mathrm{cm}^{3}\right)\end{array}$ & $\begin{array}{l}\mathrm{E}_{1 \mathrm{~mA}} \\
(\mathrm{~V} / \mathrm{cm})\end{array}$ & $\begin{array}{l}\mathrm{V}_{\mathrm{gb}} \\
(\mathrm{V} / \mathrm{gb})\end{array}$ & $\alpha$ & $\begin{array}{l}\mathrm{J}_{\mathrm{L}} \\
\left(\mu \mathrm{A} / \mathrm{cm}^{2}\right)\end{array}$ \\
\hline 0.25 & 6.3 & 5.33 & 5094 & 3.2 & 27.8 & 8.2 \\
0.5 & 5.8 & 5.41 & 5767 & 3.3 & 36.0 & 3.1 \\
1.0 & 5.0 & 5.45 & 6966 & 3.5 & 45.1 & 0.8 \\
\hline
\end{tabular}

Figure 4 shows the E-J characteristics of the samples added with different amounts of $\operatorname{Er}_{2} \mathrm{O}_{3}$. The curves markedly show that the conduction characteristics divide into a linear region
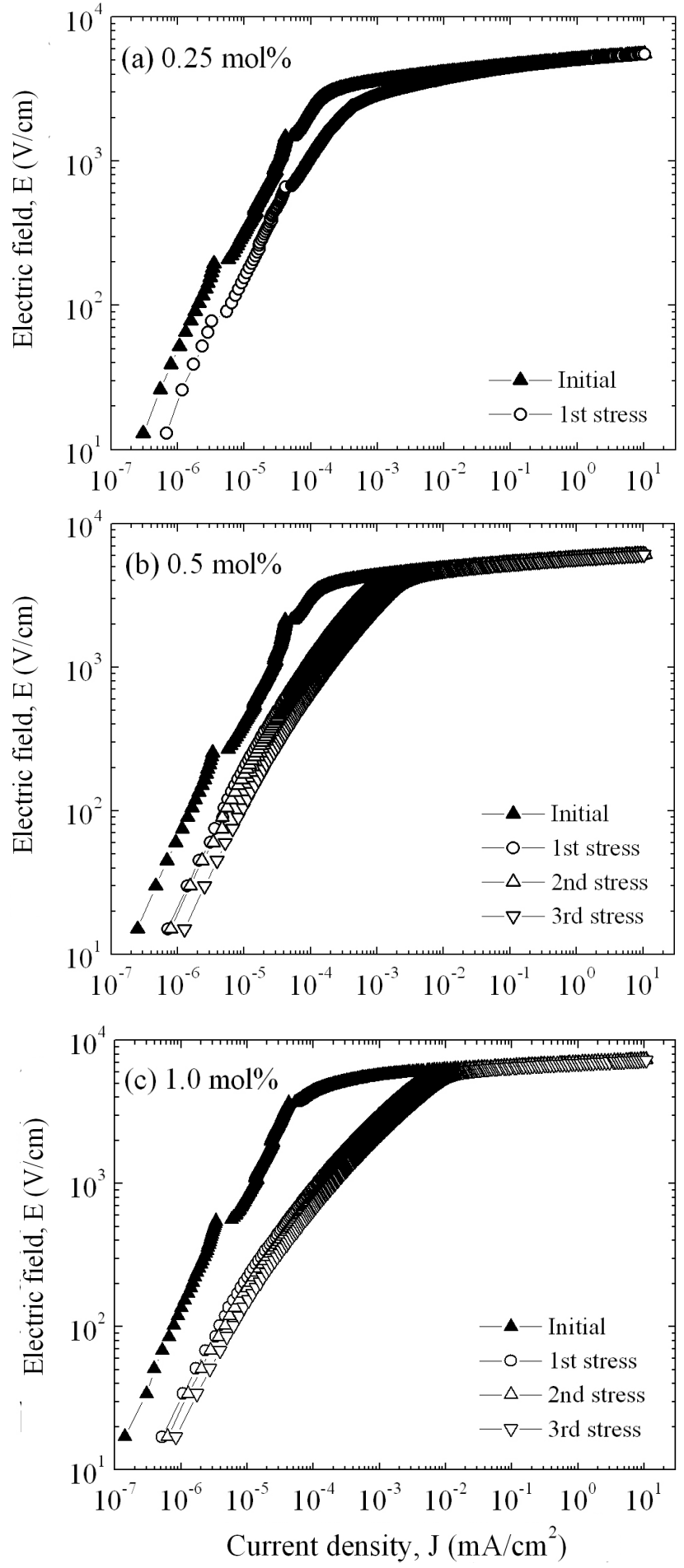

Fig. 8. E-J characteristic behavior after application of the stress for the samples added with different amounts of $\mathrm{Er}_{2} \mathrm{O}_{3}$.

with very high impedance and a nonlinear region with very low impedance. A sharper knee on the curves between the two regions indicates better nonlinear properties. However, the knee states of these curves are not distinguished by the amount of $\mathrm{Er}_{2} \mathrm{O}_{3}$.

The breakdown field $\left(\mathrm{E}_{1 \mathrm{~mA}}\right)$ greatly increased from $5094 \mathrm{~V} / \mathrm{cm}$ to $6966 \mathrm{~V} / \mathrm{cm}$ with the increase of $\mathrm{Er}_{2} \mathrm{O}_{3}$. The samples provide a high breakdown field per unit thickness. This is very effective for high voltage varistors with a compact size. The increase of 
Table 2. E-J characteristic parameters after DC-accelerated aging stress for the samples added with different amounts of $\mathrm{Er}_{2} \mathrm{O}_{3}$.

\begin{tabular}{|c|c|c|c|c|c|c|c|c|}
\hline $\begin{array}{l}\mathrm{Er}_{2} \mathrm{O}_{3} \text { amount } \\
(\mathrm{mol} \%)\end{array}$ & $\begin{array}{l}\text { Stress } \\
\text { state }\end{array}$ & $\begin{array}{l}\mathrm{K}_{\mathrm{T}} \\
\left(\mu \mathrm{A} \cdot \mathrm{h}^{-1 / 2}\right)\end{array}$ & $\begin{array}{l}\mathrm{E}_{1 \mathrm{~mA}} \\
(\mathrm{~V} / \mathrm{cm})\end{array}$ & $\% \triangle \mathrm{E}_{1 \mathrm{~mA}}$ & $\alpha$ & $\% \triangle \alpha$ & $\begin{array}{l}\mathrm{J}_{\mathrm{L}} \\
\left(\mu \mathrm{A} / \mathrm{cm}^{2}\right)\end{array}$ & $\% \triangle \mathrm{J}_{\mathrm{L}}$ \\
\hline \multirow[t]{3}{*}{0.25} & Initial & - & 5094 & - & 27.8 & - & 8.2 & - \\
\hline & lst & -17.1 & 5061 & -0.65 & 26.4 & -5.0 & 25.7 & 213.4 \\
\hline & 2nd & Thermal & & & & & & \\
\hline \multirow[t]{4}{*}{0.5} & Initial & - & 5767 & - & 37.0 & - & 3.1 & \\
\hline & lst & -0.54 & 5712 & -0.95 & 36.8 & -0.5 & 4.2 & 35.5 \\
\hline & 2nd & 0.31 & 5705 & -1.1 & 36.4 & -1.6 & 4.6 & 48.4 \\
\hline & 3rd & -0.38 & 5693 & -1.3 & 35.9 & -3.0 & 6.3 & 103.2 \\
\hline \multirow[t]{4}{*}{1.0} & Initial & - & 6966 & - & 45.1 & - & 0.8 & - \\
\hline & lst & 0.87 & 6899 & -0.96 & 43.9 & -2.7 & 5.2 & 550 \\
\hline & 2nd & 0.15 & 6894 & -1.0 & 43.6 & -3.3 & 6.9 & 762.5 \\
\hline & $3 \mathrm{rd}$ & 2.2 & 6884 & -1.2 & 42.9 & -4.9 & 9.9 & 1137.5 \\
\hline
\end{tabular}

$\mathrm{E}_{1 \mathrm{~mA}}$ with the increase of $\mathrm{Er}_{2} \mathrm{O}_{3}$ amount can be explained by the increase in the number of grain boundaries due to the decrease of average $\mathrm{ZnO}$ grain size as follows: $\mathrm{E}_{1 \mathrm{~mA}}=\mathrm{v}_{\mathrm{gb}} / \mathrm{d}$, where $\mathrm{v}_{\mathrm{gb}}$ is the breakdown voltage per grain boundary, and $\mathrm{d}$ is the average grain size. The $\mathrm{v}_{\mathrm{gb}}$ values of the samples added with $\mathrm{Er}_{2} \mathrm{O}_{3}$ were within the normal range of values of $2-4 \mathrm{~V} / \mathrm{gb}$. As a result, the $\mathrm{E}_{1 \mathrm{~mA}}$ is significantly affected by the average grain size with the increased amount of $\mathrm{Er}_{2} \mathrm{O}_{3}$, as indicated in Fig. 5.

Figure 6 shows the nonlinear coefficient $(\alpha)$ and leakage current density $\left(\mathrm{J}_{\mathrm{L}}\right)$ with the increase of $\mathrm{Er}_{2} \mathrm{O}_{3}$ amount. The $\alpha$ of the samples increased remarkably from 27.8 to 45.1 with the increase of $\mathrm{Er}_{2} \mathrm{O}_{3}$. The $\mathrm{J}_{\mathrm{L}}$ decreased remarkably from $8.2 \mu \mathrm{A} / \mathrm{cm}^{2}$ to $0.8 \mu \mathrm{A} /$ $\mathrm{cm}^{2}$ with the increase of $\mathrm{Er}_{2} \mathrm{O}_{3}$ amount. The variation of $\mathrm{J}_{\mathrm{L}}$ shows an inverse relationship to the variation of $\alpha$ in accordance with the amount of $\operatorname{Er}_{2} \mathrm{O}_{3}$. As a result, it was found that the addition of $\mathrm{Er}_{2} \mathrm{O}_{3}$ remarkably improves the E-J characteristics; namely, it increases the nonlinear coefficient and decreases the leakage current. It is clear that the values of $\alpha$ and $\mathrm{J}_{\mathrm{L}}$ were strongly affected by the amount of $\mathrm{Er}_{2} \mathrm{O}_{3}$.

The electronic and communication equipment and the electrical power systems demand high stability from the varistors in order to enhance their reliability. In practice, the $\mathrm{ZnO}$ varistors are always subjected to external stress. The degradation progresses gradually. Therefore, in addition to nonlinearity, the electrical stability is an important characteristic of $\mathrm{ZnO}$ varistors [7].

Figure 7 shows the leakage current behavior of the samples during various DC-accelerated aging stresses in accordance with the amount of $\mathrm{Er}_{2} \mathrm{O}_{3}$. The samples added with $0.25 \mathrm{~mol} \%$ $\mathrm{Er}_{2} \mathrm{O}_{3}$ exhibited a relatively high stability at the first stress $(0.85$ $\left.\mathrm{E}_{1 \mathrm{~mA}} / 115^{\circ} \mathrm{C} / 24 \mathrm{~h}\right)$. However, they exhibited instability at the second stress $\left(0.90 \mathrm{E}_{1 \mathrm{~mA}} / 120^{\circ} \mathrm{C} / 24 \mathrm{~h}\right)$, which gives rise to a thermal runaway. It is assumed that the thermal runaway of the samples added with $0.25 \mathrm{~mol} \% \mathrm{Er}_{2} \mathrm{O}_{3}$ is attributed to a low sintered density and high leakage current density. A low sintered density decreases the number of conduction paths, and eventually leads to the concentration of current. Furthermore, a high leakage current leads to high joule heat loss. On the other hand, the samples added with $0.5 \mathrm{~mol} \%$ and $1.0 \mathrm{~mol} \% \mathrm{Er}_{2} \mathrm{O}_{3}$ exhibited a much greater stability than the samples added with $0.25 \mathrm{~mol} \% \mathrm{Er}_{2} \mathrm{O}_{3}$. This is attributed to a comparatively high sintered density and low leakage current. The stability of the varistors can be estimated by the degradation rate coefficient $\left(K_{T}\right)$, which indicates the degree of aging. This exhibits the slope of the leakage current for the stress time. Lower $\mathrm{K}_{\mathrm{T}}$ values indicate greater stability. The $\mathrm{K}_{\mathrm{T}}$ of the respective samples at the third stress $\left(0.95 \mathrm{E}_{1 \mathrm{~mA}} / 125^{\circ} \mathrm{C} / 24 \mathrm{~h}\right)$ is $-0.38 \mu \mathrm{A} \cdot \mathrm{h}^{-1 / 2}$ and $2.2 \mu \mathrm{A} \cdot \mathrm{h}^{-1 / 2}$, respectively. Based on $K_{T}$, it is presumed that the samples added with $0.5 \mathrm{~mol} \%$ exhibited a slightly greater stability than the samples added with $1.0 \mathrm{~mol} \%$. The experimental facts indicate that the resistance against the DC-accelerated aging stress is greatly affected by the amount of $\operatorname{Er}_{2} \mathrm{O}_{3}$.

Figure 8 compares the variation of E-J characteristics after applying the DC-accelerated aging stress with the initial E-J characteristics in accordance with the amount of $\mathrm{Er}_{2} \mathrm{O}_{3}$. Among the E-J curves after the stress is applied, those of the linear region moved toward a higher current density. The degree of variation of E-J curves in the linear region is smaller for the samples added with $0.5 \mathrm{~mol} \% \mathrm{Er}_{2} \mathrm{O}_{3}$ than for the samples added with $1.0 \mathrm{~mol} \% \mathrm{Er}_{2} \mathrm{O}_{3}$. Therefore, the variation of E-J characteristics after applying the DC-accelerated aging stress coincided with the variation of the $\mathrm{K}_{\mathrm{T}}$ value. Table 2 summarizes the E-J characteristic parameters, and the variation rates of the breakdown field $\left(\% \Delta \mathrm{E}_{1 \mathrm{~mA}}\right)$, nonlinear coefficient $(\% \Delta \alpha)$, and leakage current $\left(\% \Delta \mathrm{J}_{\mathrm{L}}\right)$ after applying the DC-accelerated aging stress. The samples added with $0.5 \mathrm{~mol} \%$ and $1.0 \mathrm{~mol} \%$ $\mathrm{Er}_{2} \mathrm{O}_{3}$ exhibited low characteristic variation of $-1.3 \%$ and $-1.2 \%$ in $\% \Delta \mathrm{E}_{1 \mathrm{~mA}}$, respectively, and $-3.0 \%$ and $-4.9 \%$ in $\% \Delta \alpha$, respectively after the third stress $\left(0.95 \mathrm{E}_{1 \mathrm{~mA}} / 125^{\circ} \mathrm{C} / 24 \mathrm{~h}\right)$. On the contrary, the $\% \Delta \mathrm{J}_{\mathrm{L}}$ exhibited relatively high variation of $+103.2 \%$ in $0.5 \mathrm{~mol} \% \mathrm{Er}_{2} \mathrm{O}_{3}$ and $+1137.5 \%$ in $1.0 \mathrm{~mol} \% \mathrm{Er}_{2} \mathrm{O}_{3}$. However, the leakage current density of the sample added with $0.5 \mathrm{~mol} \%$ $\mathrm{Er}_{2} \mathrm{O}_{3}$ was only $6.3 \mu \mathrm{A} / \mathrm{cm}^{2}$ after the third stress. On the whole, it is carefully confirmed that the optimal amount of $\mathrm{Er}_{2} \mathrm{O}_{3}$ in the ZPCC-YE varistor ceramics may be $0.5 \mathrm{~mol} \%$.

\section{CONCLUSIONS}

The microstructure, electrical properties, and DC-accelerated aging behavior of the Zn-Pr-Co-Cr-Y-Er (ZPCC-YE) varistors were investigated for different amounts of $\mathrm{Er}_{2} \mathrm{O}_{3}$. The microstructure consisted of zinc oxide grain and an intergranular phase $\left(\operatorname{Pr}_{6} \mathrm{O}_{11}\right.$, $\mathrm{Y}_{2} \mathrm{O}_{3}$, and $\mathrm{Er}_{2} \mathrm{O}_{3}$-rich phase) as a secondary phase. As the amount of $\mathrm{Er}_{2} \mathrm{O}_{3}$ increased, the breakdown field increased from $5094 \mathrm{~V} /$ $\mathrm{cm}$ to $6966 \mathrm{~V} / \mathrm{cm}$, and the nonlinear coefficient increased from 27.8 to 45.1 . The varistors added with $\mathrm{Er}_{2} \mathrm{O}_{3}$ greater than $0.5 \mathrm{~mol} \%$ exhibited high stability by marking less than $10 \%$ in the variation rate of the breakdown field and nonlinear coefficient for DCaccelerated aging stress of $0.95 \mathrm{E}_{1 \mathrm{~mA}} / 125^{\circ} \mathrm{C} / 24 \mathrm{~h}$. These varistors could be applied for compact applications of high voltage, because they provide not only a nonlinear coefficient greater than 35 , but also a high breakdown field greater than $5000 \mathrm{~V} / \mathrm{cm}$.

\section{ACKNOWLEDEMENTS}

This work was supported by a Dongeui University grant (No. 2009AA159) 


\section{REFERENCES}

[1] C.-W. Nahm, Solid State Commun. 141, 685 (2007) [DOI: 10.1016/j.ssc.2006.12.013].

[2] L. M. Levinson and H. R. Philipp, Am. Ceram. Soc. Bull. 65, 639 (1986).

[3] T. K.Gupta, J. Am. Ceram. Soc. 73, 1817 (1990) [DOI: 10.1111/ j.1151-2916.1990.tb05232.x].

[4] A. B. Alles and V. L. Burdick, J. Appl. Phys. 70, 6883 (1991) [DOI: 10.1063/1.349812].

[5] A. B. Alles, R. Puskas, G. Callahan, and V. L. Burdick, J. Am. Ceram. Soc. 76, 2098 (1993) [DOI: 10.1111/j.1151-2916.1993. tb08339.x].

[6] Y.-S. Lee, K.-S. Liao, and T.-Y. Tseng, J. Am. Ceram. Soc. 79, 2379 (1996) [DOI: 10.1111/j.1151-2916.1996.tb08986.x].

[7] C.-W. Nahm, Mater. Lett. 47, 182 (2001) [DOI: 10.1016/S0167577X(00)00262-7].

[8] C.-W. Nahm and J.-S Ryu, Mater. Lett. 53, 110 (2002) [DOI: 10.1016/S0167-577X(01)00464-5].

[9] C.-W. Nahm, B.-C. Shin, and B.-H. Min, Mater. Chem. Phys. 82,
157 (2003) [DOI: 10.1016/s0254-0584(03)00213-x].

[10] C.-W. Nahm, J. Europ. Ceram Soc. 23, 1345 (2003) [DOI: 10.1016/s0955-2219(02)00285-6].

[11] C.-W. Nahm, Mater. Lett. 58, 2252 (2004) [DOI: 10.1016/ j.matlet.2004.01.029].

[12] C.-W. Nahm and B.-C. Shin, J. Mater. Sci. Mater. Electron. 16 725 (2005) [DOI: 10.1007/s10854-005-4975-4].

[13] C.-W. Nahm, Mater. Lett. 60, 3311 (2006) [DOI: 10.1016/ j.matlet.2006.05.079].

[14] C.-W. Nahm, Mater. Sci. Eng. B. 137, 112 (2007) [DOI: 10.1016/ j.mseb.2006.11.009].

[15] C.-W. Nahm, J. Mater. Sci. Mater. Electron. 20, 418 (2009) [DOI: 10.1007/s10854-008-9745-7].

[16] C.-W. Nahm, Ceram. Int. 36, 1495 (2010) [DOI: 10.1016/ j.ceramint.2010.02.027].

[17] J. C. Wurst and J.A. Nelson, J. Am. Ceram. Soc. 55, 109 (1972) [DOI: 10.1111/j.1151-2916.1972.tb11224.x].

[18] J. Fan and R. Freer, J. Amer. Cearm. Soc. 77, 2663 (1994) [DOI: 10.1111/j.1151-2916.1994.tb04659.x]. 